\title{
E-commerce, two-sided markets and info-mediation
}

\author{
Alexandre Gaudeul*and Bruno Jullien ${ }^{\dagger}$
}

January 26, 2005

\begin{abstract}
Participants in a market, buyers and sellers, may need the service of an intermediary who will put them into contact and give them information about their potential trading partner. The intermediary chooses what price it will charge to each side to have access to its service. It also chooses what information it will reveal, for example to the buyer about the value of the seller's product. In a market with network externalities, it would be optimal that everybody had access to the other side, as each side wants as many agents from the other side to be present as possible. This is however not feasible as the intermediary must charge positive access prices if it is to make any profit. Also, in a market with asymmetric information, it would be optimal that all information about the buyers' and sellers' valuation for the traded product be available, but the intermediary will want to conceal or manipulate that information to increase its profit. The paper examines in the first part how network externalities play out in the intermediary's access pricing strategies in both a monopoly and a competitive setting. In the second part, the paper shows how the intermediary will strategically manipulate and conceal information to extract the surplus from trade in the market it intermediates.
\end{abstract}

*University of East Anglia and CCP - Norwich, a.gaudeul@uea.ac.uk. This paper was written while I was working as a Marie Curie Research Fellow at the University of Southampton.

${ }^{\dagger}$ University of Toulouse, bjullien@ cict.fr 


\section{Introduction}

As Internet is spreading in our everyday life and business practices, it becomes clear that some of the major innovations that digital communication technologies brought concern the process of intermediation. It is at that level of the production chain that the most radical changes affecting the organization of the exchange process will occur (see for instance The Economist (2000)). Traditional brick and mortar intermediation integrates several complementary functions. On one hand, it generates, processes and transmits various information flows that are necessary for transactions: this includes information about the existence, the characteristics and the location of the products, the determination of the terms of trade (the prices) as well as some value added functions such as accounting or after-sales service. On the other hand it provides physical facilities that are used in the exchange process (transport, storage, exhibition...). Digital technologies allow for an unprecedented separation between these two types of functions, due to the drastic reduction in the cost of information processing. One can then foresee a major impact on the distribution channels and on the vertical organization of industries. While it is hard to assess at what speed this will happen, it is clear that e-commerce and electronic intermediation will play a major role in the future. It then becomes imperative to understand how a sector specialized in information management (info-mediation) can organize itself when it incurs almost no variable costs, and how competition will operate in such a sector. For our purpose, the focus will be on one of the activities of intermediaries, namely the function of identifying trading partner and assessing the quality of the potential trade.

The role of the intermediary can be divided in two parts: putting potential trading partners into contact, and providing each side of the trading relation with information about the other side. In the first function, clients of the intermediary value the diversity and breadth of offering that is proposed by the intermediary. This can be because the higher the number of sellers present at the intermediary, the higher is the probability that one of them offers a low price, or because the higher the number of buyers coming to the intermediary, the higher is the probability one will value the supplier's good highly. Network effects thus arise naturally from the function of the 
intermediary as a matchmaker. The first part of the paper is an introduction to the analysis of such network effects in two-sided markets, and to their translation in specific pricing strategies in monopolistic and competitive markets. ${ }^{1}$ The second part of the paper examines further the role of the intermediary as a manager of the relationship between buyers and sellers. While in the first part the intermediary merely acts as a meeting point for potential traders, the second part examines how it can exploit its superior knowledge of each side of the market by selling information about one side of the market to the other side. The second part therefore deals with how the intermediary exploits asymmetric information in two-sided markets.

It is difficult to find a pure example of the intermediary as a market place, i.e. where the value of the intermediary comes only from being a simple meeting-point and not from the information it gathers about participants in the market. It is similarly difficult to give a pure example of the intermediary as an expert whose role would be limited to gathering and publicizing information about the goods on a market. However, Amazon, on the one hand, and Google, on the other hand, do seem to stand at the opposite extremes.

As a bookseller, Amazon's role is to provide the widest variety of books to the largest audience. The role of Amazon as an expert for books is very limited, both because it is very easy for anybody to read by itself a summary of the book and have an idea of its value, and because it is difficult for a writer or a publishing house to mislead the consumers about the value of the product. The role of Amazon as an adviser is also limited because most of the assessments of books on its web-site are written either by the publishing houses themselves or by readers. The value of the Amazon web-site is thus in its portfolio, not in its expertise.

Google, on the other hand, does not serve as a meeting place, but as a thoroughfare: consumers use its search engine to find products. The only reason Google is valued by consumers is because it has a superior search algorithm that allows them to find information and products rapidly without fear that the search result may have been slanted toward one producer or another. Any search engine could have access to the same breadth of information as Google - the Internet is open -, but Google is better at managing that information efficiently. Producers, on the other

\footnotetext{
${ }^{1}$ See Rochet and Tirole (2004) for a more extensive survey on two-sided markets.
} 
hand, value advertising on Google because their ads will be finely targeted to consumers who actually are searching for products in the category they are operating in. Merchants can indeed buy placement on the side of Google's pages of search results. Their product is displayed only when Google users search for specific keywords of their choice. This guarantees some relevance to the advertising to which the users are exposed. Google would therefore appear as an expert in matching consumers to producers and vice-versa, while audience network effects play only a limited role. ${ }^{2}$

Those two examples, however, show how difficult it is to separate the role of the intermediary as an expert from its role as a market place: Indeed, the success of Amazon may in part be due to its expertise in categorizing its offering in ways that makes finding books easy. Google draws part of its success from its ability to scour the whole of the Internet and provide search results that would not be available from other search engines. It could also choose to increase the benefit from network effects by asking for the exclusivity on some of its search results, in the same way as the contents from encyclopedias are proprietary.

It was thus a choice for Amazon to limit itself to providing a marketplace; it didn't believe it could build a competitive advantage by providing better buying advice than other sellers. Google realized in the same way it was not worth building a proprietary portfolio of merchants to which it would link in response to search queries by consumers. It preferred to emphasize its superiority as a neutral expert in web searching.

Most intermediaries thus choose to combine a role as an expert and a role as a market-maker. They build themselves both on their portfolio of clients and on their knowledge of the market they intermediate.

While the concepts and strategies that are studied in this paper do not apply exclusively to the Internet markets, they hold specific relevance to the Internet, and this for two reasons: the first

\footnotetext{
${ }^{2}$ Google's advertising system is such that an advertiser will pay "per-click", or everytime an user clicks on its advert. It may be that Google, due to its size, is able to offer better prices than other search engines, or that advertisers would choose to confine their advertising activity to Google in order to limit the complexity of their campaign. But since there is no long-term contract between suppliers and Google, and Google does not have an exclusive portfolio of web-surfers, the network effect are probably quite low.
} 
is that Internet was thought to potentially lead to markets without intermediaries. Free access to the network and perfect information about each economic actors would make intermediaries irrelevant. Understanding why that "promise" was not fulfilled led to more reflection and a better understanding of the role of the intermediaries; an intellectual process which is reflected in the literature that is presented in this paper. The second reason follows directly from the first: since intermediation is still necessary and Internet intermediaries do play an important role in the economics of the Internet ${ }^{3}$, studying their strategies and mode of functioning is necessary both from a public policy point of view, but also to an economic actor who wants to understand what guides their pricing and what leads them to gather information on potential trading partners.

\section{Network externalities, two sided markets and intermedia-}

\section{tion}

There are network externalities when the utility derived by a particular individual from a good or a service depends on the number of individuals using it. These network effects can play between similar users (direct network effects), in which case there are linked to the nature of the good or service offered. This is for instance the case for a customer of Amazon, as the web-site offers recommendations on books to individuals based on the comparison between individual profiles and buying patterns. The more customer at Amazon, the larger the data base and the more accurate the advice provided by Amazon to its customers. This is one instance of a more general trend which sees the emergence of new ways to use the information generated within a consumption community to the benefit of this community. As another example, direct network effects are at stake in demand aggregators such as Mercata, which group orders to negotiate favorable prices with suppliers: the ability to obtain a low price is related to the ability to attract a large number of buyers.

\footnotetext{
${ }^{3}$ Henshaw (2001) report that $80 \%$ of Internet users employ search engines to locate information.

In January 2004, a Nielsen/Netrating survey ranked Google as the top Internet search destination before Yahoo, MSN and AOL.

Yahoo!, Amazon and eBay, all intermediaries, are among the few Internet success stories.
} 
Network effects can also be at work between different groups of users (indirect network effects), in particular between users buying different services at different prices. This occurs for instance when one participates to an auction web site such as e-Bay: on such a web-site sellers benefits from the participation of a large number of buyers as this ensures their chance to sell and a higher expected selling price. At the same time buyers benefits from the presence of a large number of sellers as this increase their choice set. ${ }^{4}$

Such indirect network effects are one characteristic of intermediation activities. From a more general perspective, intermediation activities are characterized by asymmetric network effects. These network effects are to a large extent linked to the informational part of intermediation. ${ }^{5}$ Buyers on an electronic platform care about the diversity of supply, while sellers care about the number of potential buyers they will have access to. There are two types of externalities involved: pecuniary externalities related to the way supply and demand affect the terms under which the exchange takes place, and non-pecuniary externalities coming from the extension of the range of products offered or demanded, and thus from the fact that at fixed exchange prices, there are more trade opportunities. Another important instance of asymmetric network effects concerns search engine and related services, where the externality is between the sites that are referenced and web-surfers. In what follows, only non-pecuniary externalities will be studied.

\subsection{A model}

The following model captures the nature of the interaction between the two parties. Consider one or several intermediation web-sites, referred to as matchmaker/s, performing an activity consisting in matching web-surfers with web-sites. On one side there is a unit mass of web-surfers forming a continuum. These web-surfers pay a price $p$ to access the web-site. Denote $n$ the mass of web-surfers choosing to register. On the other side there is a unit mass of web-sites. The web-sites pay $P$ to be listed by a matchmaker. Denote by $N$ the mass of web-sites registering.

\footnotetext{
${ }^{4}$ There are also negative externalities between buyers as the prices depends on the level of supply on the marketplace (see Baye and Morgan (2001)).

${ }^{5}$ There may also be some consumption externality in transportation due to economies of scale, but they don't have the same asymmetric nature.
} 
Matching is done as follows. For each client registering there is a cost $c$ to collect and treat the client's information (for conciseness, it is assumed that the cost is the same for both sides). Assume that intermediaries are essential so that no match can be performed without the help of an intermediary. This is an extreme assumption but it makes sense in some cases where there are many agents supporting large search costs in the absence of some electronic intermediation.

Once an agent has registered with the intermediary, the latter introduces its characteristics within its database, and grants it access to a technology that performs search in this database. The performance of the market under three scenarios will be compared:

- A competitive access to a global database: All intermediaries share their information. Any agent connected to the database has access to the whole information on all connected agents, and access is provided by all intermediaries under perfect competition. Intermediaries thus act as access providers.

- A monopoly intermediary: A monopoly builds a proprietary database of its customers. To be put in relation with a site or a web-surfer, it is necessary to register with the monopoly.

- Imperfect competition between several intermediaries: Each intermediary builds a proprietary database of its customers. Only customers of the intermediary have access to its database.

Assume that when a web-site and a web-surfer are connected, they establish a non-merchant relationship, or the nature of the trade and the exchange price are not affected by the registration fees $p$ and $P$. This supposes in particular that the intermediary only performs a matching function, and doesn't intervene on the trading process between the web-site and the web-surfer.

To simplify, assume that payoffs are linear. A web-surfer receives an expected surplus $f N$ from accessing a database with $N$ web-sites, where $f$ is the same for all web-surfers. The interpretation is that the probability to find a partner is linear with the size of the population of web-sites and that the expected gain from trade is fixed, hence a linear relationship between the mass of web-site registering and the value of participating for a web-surfer. Web-surfers differs 
in their opportunity cost to participate to the market. This cost can be seen as the cost of time spent on the activity, or as the reflection of different values assigned to alternative activities. Each individual bears a personal cost of access that varies within the population. Individuals will access the market by increasing order of access cost. Define $a(n)$ to be the total access cost of the web-surfers when a mass $n$ of them decides to access the market. The derivative $a^{\prime}(n)$ is the access cost of the marginal participant: when the number of participants increases by $d n$, the new participants support an access cost $a^{\prime}(n)$. In other words there is a mass $n$ of web-surfers with an access cost smaller than $a^{\prime}(n)$. Since the latter arrival incurs a higher cost than the former participants, the function $a(n)$ is convex and $a^{\prime}(n)$ is increasing.

Consider here the case of a single large data base, which obviously is efficient from a purely technical perspective.

Given a registration price $p$ and a mass $N$ of web-sites, a web-surfer will choose to register if its expected benefit is positive, where the benefit is the gross expected utility $f N$ net of the price $p$ and of the access costs. The number $n$ of web-surfers participating is thus given by:

$$
a^{\prime}(n)=f N-p .
$$

The net total surplus of web-surfers is then

$$
s=f N n-a(n)-p n .
$$

Similarly assume that each web-site derives a surplus $F n$ from its participation when this gives access to $n$ web-surfers. Like for the web-surfers, the cost of registering and providing the relevant information to the intermediary is variable among web-sites. Let $A(N)$ be the total access cost of web-sites when a mass $N$ of them registers. For the same reason as above, the total cost $A(N)$ is convex, and the mass of web-sites registering is related to the mass of web-surfers by the expression

$$
A^{\prime}(N)=F n-P
$$


where $P$ is the registration price for web-sites. The net surplus of web-sites is then

$$
S=F n N-A(N)-P N
$$

In this set-up, the total profit is $(p-c) n+(P-c) N$, and the total surplus $W=s+S+(p-$ c) $n+(P-c) N$ generated by the market is

$$
W=(f+F) n N-a(n)-A(N)-c(n+N) .
$$

This shows that the market involves network externalities. The utility derived by a participant on one side of the market depends on the mass of participants on the other side of the market. This is referred to as a two-sided externality (see Armstrong (2002), Rochet and Tirole (2002)).

Ignoring any budget balancing condition, the maximization of the total surplus requires that the participation levels verify

$$
\begin{aligned}
& (f+F) N-a^{\prime}(n)-c=0 \\
& (f+F) n-A^{\prime}(N)-c=0 .
\end{aligned}
$$

This is achieved by setting prices equal to

$$
\begin{aligned}
& p=c-F N, \\
& P=c-f n,
\end{aligned}
$$

which accounts for network externalities. The participation of an additional web-site raises the utility of each web-surfers by an amount $f$. As a consequence, to achieve optimality, it is necessary to give to each web-site a subsidy equal to its total contribution $f n$. Total surplus maximization thus requires to price access below cost, and thus to run a deficit.

When external subsidies are not available, the social optimum is obtained when maximizing 
the surplus $W$ under the zero profit condition:

$$
p n+P N=c n+c N
$$

A direct computation then shows that this leads to set prices such that the following conditions are verified:

$$
\begin{aligned}
& p=c-F N+\frac{\lambda}{1+\lambda} n a^{\prime \prime}(n) \\
& P=c-f n+\frac{\lambda}{1+\lambda} N A^{\prime \prime}(N)
\end{aligned}
$$

where $\lambda$ is the shadow value of the zero profit condition. Optimal prices are not equal to marginal costs. Typically, since total profits vanish, the price faced by one side of the market should be below marginal cost, which is compensated by a positive margin on the other price. As emphasized in Armstrong (2002) or Caillaud and Jullien (2001):

The optimal pricing scheme involves cross-subsidies between the two sides of the market, a general characteristic of two-sided markets.

Which side on the market should be subsidized then depends on two considerations. The side of the market that generates the highest externality should claim for a subsidy. But this must be balanced by budgetary considerations of the Ramsey type, so that the price structure should also be shaped in favor of the side whose participation level is the most responsive to prices.

A competitive access to a global database leads to access prices

$$
p=c, \quad P=c
$$

The prices are equal to the marginal cost of including the customer in the network. Due to the presence of network effects these price are inefficient:

\section{Competitive access pricing leads to an inefficient allocation of resources.}

The key point is that an access provider cannot recoup the entire surplus that its service generates since customers of other access providers benefit from the participation of its customers. 
Thus competitive access leads to complementarities between intermediaries that the market does not internalize. Achieving proper internalization would require creating a system of compensations, which would be equivalent to imposing access charges to the database of each intermediary.

Suppose now that the intermediation is ensured by a monopolist. Then the monopolist maximizes its profit: ${ }^{6}$

$$
\Pi=(p-c) n+(P-c) N
$$

or

$$
\Pi=(F+f) n N-a^{\prime}(n) n-A^{\prime}(N) N-c n-c N
$$

The prices are then set at levels

$$
\begin{aligned}
& p=c-F N+n a^{\prime \prime}(n) ; \\
& P=c-f n+N A^{\prime \prime}(N) .
\end{aligned}
$$

The monopolist internalize the network effects but introduce a mark-up over the net social cost. It is easy to see that there are cases where even a monopoly would choose to subsidize one side of the market by setting a price below cost (say $p<c$ ) and recovering the loss by having the other side pay a large fee for their participation. This will occur when the valuations that the two sides assign to the service are asymmetric.

One conclusion from the comparison between a monopoly and a competitive access system is that info-mediation markets are more complex than traditional "make and sale" markets, or even standard "buy and resale" intermediary markets. The complexity is coming in part from the ability of the intermediary to set different access prices for each side of the market. For, suppose that the intermediary could not know the identity of customers nor the use they make of the database (for instance on stock exchanges, the same individual may be a buyer or a seller during the same session so that it is not possible to charge different registration fees). The monopolist

\footnotetext{
${ }^{6}$ Assume here that the monopolist can control quantities. Due to coordination failure problem, there may exist several allocation compatible with a given price structure, so that price control may not suffice to achieve monopoly profits.
} 
charges the same price for all users and this price is above marginal cost. In this case, competition dominates a monopoly market structure unambiguously.

Thus the monopolist's advantage is the ability to set different prices and to cross-subsidize. That type of cross-subsidy calls for a more detailed discussion in the context of imperfect competition, and this for two reasons. First, the analysis suggests that the optimal market structure may obtain with a limited number of intermediaries under imperfect competition, as a way to balance coordination and the exercise of market power. Second, the use of cross-subsidies generates very aggressive pricing strategies to capture customers, which are specific to this type of markets.

\subsection{Competing intermediaries}

Assume now that intermediation services are provided by two intermediaries $A$ and $B$. The intermediary $k$ sets prices $p_{k}$ and $P_{k}$ for the web-surfers and the web-sites respectively. Unlike the competitive access case, a customer of an intermediary has access only to that intermediary's database and thus only to its customers. Assume in addition that a customer can register only with one intermediary (see the discussion below).

For this discussion, simplify matters further by assuming that access costs are constant and equal to zero. As this is the most interesting case, concentrate on the case where there is a strong asymmetry between the two sides so that $F>2 f$. Under those assumptions, a monopoly intermediary can charge maximum prices $p=f$ and $P=F$. The allocation is efficient but the entire surplus is captured by the monopolist. In this context a competitive access system would allow users to enjoy the full surplus but the allocation may be inefficient. In particular if one side of the market has a low value for the connection to the other side ( $f$ smaller than $c)$, there will be no exchange at all as no one participates.

Consider the case of two competing intermediaries. Competition is taken under its extreme Bertrand type: each agent joins the intermediary offering the highest utility. Then, when the price differential between the two intermediaries is smaller for each side than the value of intermediation, $f$ and $F$, the allocation of consumers is indeterminate due to network effects. There are 
two possible equilibria in the allocation of consumers: in both, all agents register with the same intermediary, but any of the two intermediaries can emerge as the winner. In such a setting, the outcome of competition will be affected by prices but also by the expectations of each individual on the behavior of the other side of the market: whether an individual register with $A$ or $B$ depends on whether it expects the other side to do so. Our purpose here is simply to illustrate some of the mechanisms at work when info-mediaries compete. ${ }^{7}$ To do so, an equilibrium which corresponds to the maximal profit equilibrium will be exhibited.

Notice that in our very simple set-up, an efficient equilibrium is one where all agents register with the same intermediary, say $A$. In equilibrium at least one of the prices of the intermediary $A$ must be above cost. Given that web-sites attach a higher value to reaching the web-surfers than those attach to reaching a web-site, intuition suggests that web-sites should be the profitable side of the market. So let us take for granted that they face a price above $c$.

Given the prices of $A$, consider the options of the other intermediary in terms of tarification. As follows from above, if the price differential with $A$ is smaller than $f$ and $F$ respectively, $B$ faces the risk of not attracting anybody. To be sure to attract some customers, $B$ must thus undercut $A$ by a large amount on at least one side. But then the possibility of cross-subsidy generates pricing strategies that are very contrasted between the two sides of the markets. For instance, in order to attract the web-surfers with certainty, $B$ must undercut the price of $A$ for web-surfers by an amount $f$ (implying a negative price and thus a subsidy or a gift). Let us mention that what is meant here by a negative price is not necessarily a payment to the websurfers. This rather translates into the fact that some services will be offered free of charges, or that the intermediary will spend a lot in the acquisition of the audience. The subsidy here is chosen so that web-surfers joins $B$ even if web-sites register with $A$. Its purpose is for $B$ to create a value for the web-sites and it is only justified if it allows attracting the web-sites at a price that compensates the loss on web-surfers. Given that no web-surfers join $A$ at this price if $B$ decides to undercut by an amount $f$ the price for web-surfers at $A, A$ looses its value for the web-sites. Then the web-sites are willing to join $B$ at a price up to $F$.

\footnotetext{
${ }^{7}$ See Caillaud and Jullien (2001) and Caillaud and Jullien (2003) for a more extensive analysis.
} 
To summarize the discussion, by under-cutting the price of web-surfers by $f$, the intermediary $B$ can generate a profit $F-c$ on the web-sites. This implies that the profit generated by intermediary $A$ on the web-surfers cannot exceed $f-(F-c)$. Given that $F-c$ is an upper bound on the profit obtained by the intermediary $A$ on web-sites, the total profit that intermediary $A$ can expect is less than or equal to $f$, the value of the service for the side of the market with the smallest willingness to pay for participation. Following the analysis in Caillaud and Jullien (2003), one can show that there is indeed an equilibrium in which the intermediary $A$ monopolizes the market with this maximum profit. This can for instance be achieved with prices $f-(F-c)+c$ for web-surfers and a price $F$ for web sites.

This example illustrates that the nature of competition that takes place between intermediaries on electronic markets is quite different from the nature of the competition between producers of final goods, the difference coming from the network interactions inherent to the intermediation activity.

Competition reduces profits but needs not eliminate them completely, even in the absence of any differentiation between service providers. In the relevant case where $f$ is smaller than the monopoly profit, the profit cannot exceed the value of intermediation for any side of the market. In the simple case discussed before, this reduction in profit is not related to any efficiency consideration as the allocation is the same for a monopoly market structure or a duopoly (this obviously is not general). As was suggested by the preceding section, an imperfectly competitive market structure with several intermediaries having proprietary databases may dominate a monopolistic market structure - which is not a surprise - but it can also dominate a competitive access system with a global database, which is more surprising. This occurs when the value of intermediation is small for the web-surfers; $f<c$. Indeed, in that case, competition between proprietary databases results in the participation of both sides into the market while a competitive global access system would not generate participation, and this is achieved with low profits for the intermediary, unlike in the monopoly case.

Thus, one conclusion from this analysis is that the optimal market structure for info-mediation 
markets is a situation of competition between a limited number of actors. This is true from a positive perspective, as due to network effects there are barriers to entry in these markets. This is also true from a normative perspective as this allows finding a compromise between the need to internalize network effects through some cross-subsidization, and the distortions in the level of prices that market power induces. As usual when this occurs, one issue is obviously that if the competition is too intense with several intermediaries and there are significant entry costs, the market structure will not be optimal and may even turn out to be a monopoly, as no other firm may be willing to sink the entry cost to compete.

The analysis also provides a rationale for the common practice on the Internet of granting free access to one side of the market. Free access emerges when one side should be subsidized but the service provider cannot discriminate between potential users and money-grabbers.

More generally it shows that cross-subsidies are exarcerbated by competition, a conclusion that contrasts with the analysis of traditional markets. Indeed, in markets with no network effects or nor possibility to link the price faced by a customer to the specific network externalities that its participation generates, competition tends to reduce the margins over marginal costs, and thus to reduce any form of cross-subsidy or more generally of price-discrimination.

Exploring further the logic behind this type of models then shows that these conclusions are reinforced once other specificities of digital technologies are taken into account, such as sophisticated pricing, discrimination or multi-homing.

\section{Asymmetric information and info-mediaries}

Instead of looking at the role of the intermediary as a matchmaker, this part deals with the role of the intermediary as an expert. In a market where buyers are imperfectly informed about the value of the sellers' products, trade may not be possible. Suppose for example that the expected value of a product in a category in which there are many sellers is negative but some sellers have products with positive value. Suppose also that the seller cannot prove the value of its product to the consumer, as can happen if they trade exclusively over the Internet. Its product then cannot be 
sold as its expected value is negative; no claim that the product is valuable can be trusted, since all sellers are motivated to make that claim. On the Internet, those information asymmetries are exacerbated because the consumer cannot touch the product and assess its quality ${ }^{8}$, while guarantees are difficult to put in place: the seller's credit worthiness may be questionable. Even if the product is digital, a software for example, and could theoretically be tested before buying, it is not possible to monitor its use. A consumer would then be tempted to return the software and pretend it was not valuable, while keeping on using it on its computer, unchecked.

The intermediary may be relied on to prevent such a market failure: an intermediary, defined as a long-term player on the market with a superior knowledge of the supplier's good's quality and with a large portfolio of clients, will be trusted to say the truth about the supplier's good. Indeed, its interests are not linked to the welfare of any specific participant in the market, while it will want to provide objective advice to consumers: its reputation as a reliable information provider is its only stock in trade. Its profits being linked to the quality of the information it provides, it will also be motivated to invest in certification technologies that allow it to accurately assess the quality of the goods it intermediates.

There are therefore three main claims for the usefulness of intermediaries:

- Neutral third parties: Intermediaries solve the adverse selection problem in markets with asymmetric information as they are not linked to any parties in the trade.

- Reputation rent-seekers: Intermediaries will not lie about the seller's quality so as to preserve their reputation and the profits it engenders.

- Experts: Intermediaries turn soft, un-verifiable information about a supplier's product into hard, certifiable information.

The rest of this part examines those roles and how intermediary play them. A monopoly intermediary may want to profit from its information on a supplier's product not by revealing it,

\footnotetext{
${ }^{8}$ The consumer may have access to more information about the product via the Internet than it could through other channels, but the physical world will always potentially offer a wider range of learning experiences in a more credible way. "Those who have not seen and yet believe will be blessed", but more often than not they are deceived...
} 
but by hiding it in exchange for payment. This is the paradoxical "minimal information" result whereby all suppliers seek the certification of the intermediary but the intermediary's certification doesn't reveal any information to the customer beyond what it already knew about the supplier.

In a competitive setting, an intermediary will reveal the type of the supplier, but then, there are concerns about the motivation for suppliers to bribe the intermediary into lying about their type. This will be shown not to happen in equilibrium, unless consumers are naïve and do not anticipate bribe taking.

Before going on, note that the models presented here differ from the principal-agent models with an outside auditor who monitors the relationship (Khalil and Lawarree (1995) and Baron and Besanko (1984)): there is no hierarchical relationship between the trading parties, and no moral hazard from one or the other side. The type $t$ of the good that is traded is not a variable in the model: effort in producing the good has already been expended.

The cases that are discussed here also differ from search and reputation models dealing with situations of asymmetric information in bilateral trade between buyers and sellers (Milgrom (1981), Grossman (1981), Crawford and Sobel (1982), Okuno-Fujiwara, Postlewaite, and Suzumura (1990) and Wolinsky (1993)). Instead of a situation where a player (seller, expert) wants to transmit its own type to another agent (buyer, decision maker), here, an intermediary must try to find out the type of the supplier before transmitting it to the buyer.

\subsection{A model}

The typical model of information intermediation that serves as the basic building block for the discussion is presented below:

There are three types of agents, buyers, sellers and intermediaries. Buyers and sellers may use the services of the intermediary to assist them in their transactions. The seller owns a good of type $t$ which it values at 0 . The consumer values a good of type $t$ at $t$. The seller knows $t$ but cannot credibly signal it to the consumer (soft information). The intermediary has a technology 
to test goods at $\operatorname{cost} c$, which allows it to know $t$.

The timing of the game is as follow:

1. The intermediary sets an array of prices $P$ and disclosure rules $D$ to maximize its profits. $P$ is the price vector for its service to consumers and sellers. Disclosure rules specify what information the consumer will be given about $t$.

2. The supplier decides whether to use the service of the intermediary, knowing $P, D$ and its own type $t$.

3. If the supplier uses the service of the intermediary, then the intermediary may choose to pay cost $c$ to discover $t$.

4. The consumer observes $P, D$, the decision of the supplier to use the service of the intermediary and the intermediary's revelation, $R(t, D), R$ being determined by the disclosure rule which assigns a message to each supplier's type.

5. The consumer decides whether to buy the seller's good.

\subsection{The minimal information result}

Suppose the intermediary is a monopoly. Note that the monopoly setting is not merely a way to introduce the more complicated competitive setting. Most papers study only a monopoly setting by arguing like Strausz (2003) that there are increasing returns to scale to certification: the bigger the potential loss from lying, the higher the motivation not to lie and the better the reputation of the intermediary, who can then out-price the competition. Intermediation would then be a natural monopoly. The certifier may also be a State-mandated monopoly, as happens if it is appointed the management of a government mandated certification process.

Lizzeri (1999) will be used to study the base case scenario, and is therefore presented in detail: There is an intermediary and many suppliers who want to sell goods valued at $t$ by consumers, 
but consumers do not know $t$ and know only its distribution among suppliers, $F$ over $[0,1]$. The intermediary is able to certify the product of the supplier of type $t$ and in that case, it can be sold at $t$. The intermediary sells its certification service at $p$, the same for each suppliers.

Suppose the intermediary tells $t$ to consumers once the supplier paid $p$. The supplier then makes profit of $t-p$. Since $p>0$, not all suppliers will seek certification. Only suppliers with $t>t(p)$ will seek certification. The ones who don't must sell their goods to consumers who know that their type is below $t(p)$, and thus make profit of $E[t / t<t(p)]$. The threshold type is thus $t(p)$ such that

$$
t(p)-p=E[t / t<t(p)]
$$

and the intermediary makes profits of

$$
\Pi_{I}=p \times(1-F(t(p))
$$

Note that an equilibrium where suppliers of type $t>t(p)$ go to the intermediary while others don't is sustained by consistent beliefs: if consumers believe suppliers conform to that equilibrium, then suppliers will do so, and conversely.

However, the intermediary may be able to manipulate beliefs in a more profitable way than simply revealing $t$ if $p$ is paid. Looking at the profit function above, the intermediary wants many suppliers to come use its service (potentially all) while charging them a positive price. This can be done by setting price $E(t)$ for its service and not revealing anything about the type of the supplier, except that it is not of type 0 . In that equilibrium, beliefs of consumers are such that a supplier who doesn't get certified is assumed to be of type 0 . That equilibrium is sustained by consistent beliefs.

The disclosure rule such that $D=\emptyset$ if $t>0, D=0$ if $t=0$ thus supports an equilibrium that is optimal for the intermediary as it gets the whole surplus $E(t)$ from the market. However, the beliefs that sustain it may seem arbitrary, and indeed, consumers may entertain other beliefs that get lower profits for the intermediary (They may believe for example that no supplier goes to 
the intermediary except the lowest type, resulting in profit 0 for the intermediary). Lizzeri (1999) shows that the intermediary can induce favorable beliefs under some conditions - see appendix A.

Lizzeri (1999) thus shows that under some condition on the distribution of the type of the suppliers, then the intermediary doesn't reveal any information about $t$ to the consumers. Even though there is no benefit for suppliers in using the service of the intermediary, all suppliers still are ready to abandon the whole surplus from trade to the intermediary. This is supported by the consumers' belief that a seller who doesn't go to the intermediary is of the lowest type. Not going to the intermediary is interpreted as a bad signal on the type of the seller, and no buyer will buy from a seller that is not certified. Therefore, all sellers need to go to the intermediary to perform any sale. The intermediary sets its price as the difference between what the supplier will get by going through the intermediary and what it would get if it was the worst type. The only information the consumer gets is that a supplier that is certified is not of the worst type. The intermediary thus acts like a parasite that both buyers and sellers would want to get rid off, but whose mere presence makes it indispensable. Is this what is observed on the Internet? No, as intermediaries do seem to provide information about products by ranking them, giving advice, etc. That information would not be accessible without them. Does this invalidate Lizzeri's point?

Not necessarily, as Guerra (2001) extends Lizzeri's minimal information result to explain why intermediaries give some (but not all) of their informations. The consumer now has some information $t_{e}=t+\theta$ about the supplier's type $t$ with $\theta$ i.i.d. The supplier can sell its product at $p\left(t_{e}\right)$ if $t_{e}$ is the only information the consumer has, and at $p(t)$ if the intermediary certifies its product as $t$. The graph on the left below shows what happens when the consumer has no information about $t$ : the intermediary's profit will be maximized by setting a threshold $t_{i}$ under which it doesn't certify the product, and getting the supplier to pay for the difference between the expected value of its product without certification vs. its value with certification. The graph on the right below shows what happens if $t_{e}$ increases with $t:$ setting a single threshold $t_{i}$ results in suppliers with a high $t$ not wanting to pay the price of certification because consumers will already 
know their type is higher than $t_{i}$. The intermediary is then better off setting several intervals of certification, $\left[t_{1}, t_{2}\right],\left[t_{2}, t_{3}\right],\left[t_{3}, t_{4}\right], \ldots$ with associated prices $p_{1}, p_{2}, p_{3}, \ldots$. The intermediary assigns suppliers into classes so as to offer the consumer just enough information so as to prevent the supplier from bypassing the intermediary.

\section{(Graph 1 p. 21)}
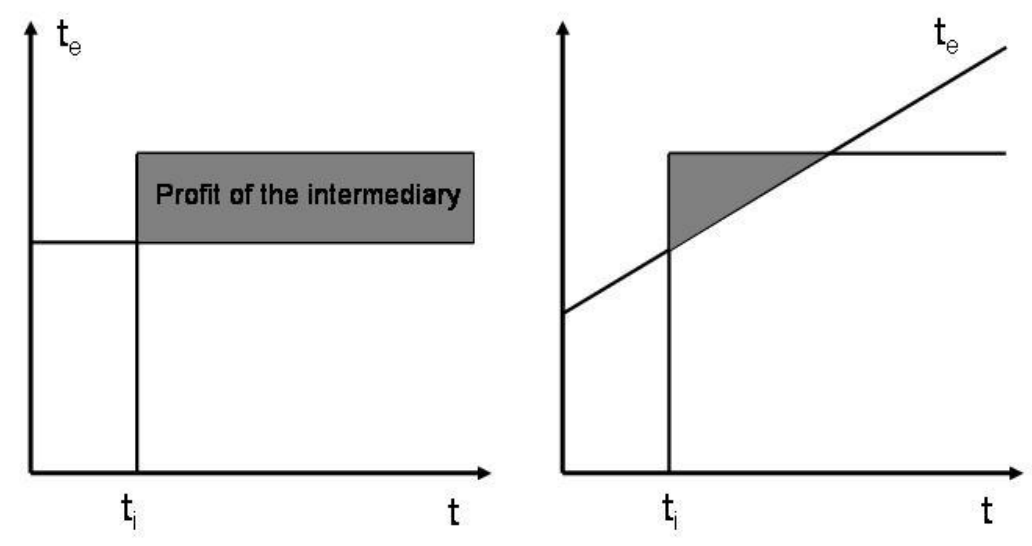

Figure 1: Lizzeri vs. Guerra

The negative result in Lizzeri (1999) thus doesn't hold if the consumer has some information about the suppliers. It does not hold either if the consumer's utility function exhibits risk aversion: Peyrache and Quesada (2004) shows that in that case the intermediary will transmit information about $t$ beyond simply saying whether trade is efficient or not. With risk aversion, $t$ is revealed fully if it is above some threshold level, while nothing is said about those suppliers whose type is below that threshold. The disclosure rule is therefore such that $t$ is revealed fully for $t \geq x$ for some $x>0$, while nothing is revealed for $t<x$. The intermediary reveals more information than in Lizzeri (1999) because it plays an additional role which is to reduce uncertainty in the market. It thus can increase the expected surplus from trade by disclosing information about the supplier, a surplus from trade it then appropriates. As a monopoly, of course, it will set the threshold $t$ such as to maximize its profit, and not the global surplus. This is why no information will be disclosed for $t$ below a threshold. Peyrache and Quesada (2004) introduces another role for the 
intermediary: it relaxes price competition between the suppliers by allowing them to differentiate their product through certification. This leads it in the same fashion as above to disclose more information about the suppliers.

The monopoly intermediary thus reveals information about $t$ when its role in the relationship buyer-seller is not only strategic (which side is going to get what share of the surplus of trade), but also productive (reducing uncertainty, alleviating competitive pressures, etc...).

\subsection{Collusion}

Lizzeri (1999) assumed that the intermediary couldn't lie about $t$ : its disclosure rule was public. The monopoly intermediary would not disclose any information about $t$ in equilibrium. However, consumers and suppliers are best served by an intermediary that reveals $t$ and sets its fee to 0 . Competition between intermediaries leads to the adoption of that strategy. There is thus revelation of information, and consumers pay $t$ for a product that is certified as $t$ while the intermediaries make zero profit. What happens then if the intermediary can lie about $t$ ? In a one-period setting, the intermediary will always want to take a bribe from a supplier to pretend that its type $t$ is high. This adverse selection problem may then prevent trade from happening.

Peyrache and Quesada (2003) show however that if consumers correctly anticipate the risk of bribe taking and the game is repeated, then there will be no bribe taking. Indeed, suppose consumers react to a lie about $t$ by the intermediary by not using its service anymore in future periods. Suppose profits from accepting a bribe today is $B$ while future discounted profits lost by lying is $\Pi$, and the intermediary accepts bribes with some probability $\lambda$. Either $B>\Pi$ in which case the intermediary will always accept bribes and its certificate doesn't convey any information, or $B=\Pi$ and $\lambda \in] 0,1[$. Knowing $\lambda$, consumers will update their belief about $t$ based on the message of the intermediary. If for example it is profitable for a supplier of type $t_{1}$ to pay the bribe so as to obtain a certificate $a$, consumers will interpret $a$ as $t_{1}$ and will not be ready to pay more than if the intermediary had told the truth. This can be generalized to say that the intermediary cannot sell a false report at any positive price $(B=0)$ so that the intermediary will lie if and only 
if $\Pi$ itself is 0 . But $\Pi>0$ as long as the intermediary can charge positive prices to suppliers or consumers. Therefore, in the general case, the intermediary never lies about $t$ even if it is subject to bribes. That equilibrium is fragile however; the consumer must be able to estimate the profits of the intermediary, its incentive to accept bribes and it must also be able to detect deviations on the part of the intermediary.

Those are strong assumptions since most consumers do not even know that many search results on search engines are sponsored. While sponsorships and bribes are two different things, this suggests that consumers are also unaware of the risk of getting biased reports. Most models of bribe taking thus assume that the consumer is naïve: it doesn't fully anticipate bribe taking. In that case, lying may be a profitable short term strategy, and asking bribes to do so is enticing. The consumer will deter such behavior by basing its strategy on the ex-post realization it was lied to (when the supplier that was certified proved to be of another type than what the intermediary said). Additionally, instead of assuming that any consumer's report of a lie by an intermediary is immediately conveyed and believed by all, it is more reasonable to assume that consumers can punish the intermediary only at their individual level. Indeed, if consumers believed any report of a misbehavior by an intermediary, a competitor would fabricate such report.

Suppose therefore consumers take a report $t$ at face value and do not have any other information about the type of the supplier than what the intermediary tells it. If no bribes are offered, and the intermediary sets the price of certification at $p$, then any supplier of type $t(p)$ such that

$$
t(p)-p \geq E(t / t \leq t(p))
$$

will seek certification. Maximization of profit with respect to $p$ leads to setting a certification threshold level at $t_{I}^{*}$ and $p^{*}=t_{I}^{*}-E\left(t / t \leq t_{I}^{*}\right)$. Any supplier of type $t$ more than $t_{I}$ gets its product certified as $t$.

Suppose now, w.l.o.g., that the intermediary, before getting to know the type of the supplier, offers to certify the supplier as being of the highest type $\bar{t}$, and this at cost $b$ (bribe). A supplier 
of type $t \geq t_{I}$ would then be able to sell its product at $\bar{t}$ and will bribe the intermediary if it can make higher profits that way than by paying $p$ and being certified as being of type $t$ :

$$
\bar{t}-b \geq t-p
$$

Suppliers of type $t \leq t_{I}$ bribe only if :

$$
\bar{t}-b \geq E\left(t / t \leq t_{I}\right)
$$

Therefore, no supplier will bribe if $b \geq \bar{t}-E\left(t / t \leq t_{I}\right)$, all will if $b \leq p$, while for $b \in$ $\left[p, \bar{t}-E\left(t / t \leq t_{I}\right)\right]$, some suppliers will choose to bribe the intermediary. The intermediary will then be trusted to reveal valuable information only if the maximum bribe $b=\bar{t}-E\left(t / t \leq t_{I}\right)$ it could get is low. That means $p$ must be high as then, only suppliers with a high type $t$ get certified, so that $E\left(t / t \leq t_{I}\right)$ is high and as a consequence $b$, the bribe that can be obtained, is low. Strausz (2003) shows that the intermediary will indeed react by setting a higher price for its certification than if it was not subject to bribes. The intermediary will thus exclude more suppliers from the market than if it was a monopoly with no concern for bribe taking.

In competition the intermediary is forced to lower its price compared to the monopoly outcome. The previous analysis would seem to mean it is then more subject to bribe taking. There is then a potential degradation of the quality of certification due to competitive pressures. Gaudeul (2003) shows that competition may in fact improve the quality of certification. Suppose the intermediary has a portfolio of consumers (mass 1). There are two types of suppliers, type high whose product can be sold to $\bar{t}$ consumers at price $\bar{p}$, and type low whose product can be sold to $\underline{t}$ consumers at price $\underline{p}$. Consumers buy a product if told to do so by the intermediary, and find out the type of the supplier afterwards. Suppose $1>\bar{t}>\underline{t}$ and $\bar{p}<\underline{p}$. The honest intermediary can acquire hard information on the supplier's product at cost $c$ and then get the appropriate number of consumers to buy it. The dishonest intermediary will announce a supplier of type $\underline{t}$ is of type $\bar{t} . \bar{t}$ consumers will then buy the product. $\bar{t}-\underline{t}$ will be disappointed and will not return to the 
intermediary the following period.

In the monopoly setting, intermediaries with a high discount factor will be honest because they want to keep customers. In competition, consumers who are not directed by an intermediary go to another. This will be shown to increase the incentive to be honest: When the intermediary announces a supplier of type $\underline{t}$ is of type $\bar{t}, 1-\bar{t}$ consumers go to another intermediary this period instead of $1-\underline{t}$ if the intermediary had told the truth. Lying therefore loses consumers for the lying intermediary next period, but it also hurts competitors this period, which means it will reduce the price the lying intermediary can charge. Indeed, those competitors react to a deviation from truthfulness by offering suppliers or consumers more advantageous terms so as to discourage them from listing or buying at the deviating intermediary. This means that deviating starts a price war in addition to losing consumers. Any intermediary who would have been honest in a monopoly setting will therefore be honest in a competitive setting. ${ }^{9}$ A competitive intermediation system is at least as stable as a monopolistic one as long as intermediaries are able to observe each other's pricing and recommendations strategies.

The models above apply to search engines, but there are other types of info-mediaries that are important to the functioning of the Internet; those companies such as Verisign that certify the compliance of a merchant's web-site with some pre-defined rules of operation (privacy policy, credit worthiness, etc.). Those intermediaries of trust either certify the web-site or do not. Hvide (2002) thus considers a situation where intermediaries offer only binary reports ("pass" or "fail") to the consumers. Instead of having a grid in which suppliers are ranked, the intermediaries only disclose whether the supplier passed or failed their test. Hvide (2002) shows a two-tiered system will arise in competition. Suppliers of a good type will get certified by the intermediaries who deliver certificates ("pass report”) with lower probabilities, and information about the seller's type is thus conveyed by which intermediary it got certified by. The intermediaries who certify the

\footnotetext{
${ }^{9}$ For the same type of reason, an intermediary who would have incurred cost $c$ to know the type of the supplier may not do so in competition. Indeed, knowing the type of the supplier allows the intermediary to better fine tune its advice to consumers, and thus direct more consumers each period. As explained above, directing more customers each period exacerbates competitive pressure, which explains why this more efficient system is used less often in competition. The intermediary prefers giving less information to reduce competitive pressure at the expense of directing a bit less consumers each period.
} 
highest type are the ones who make the highest profit, and those higher profits ensure they certify truthfully (they want to keep their reputation as a certifier of high quality sellers). Suppliers self-select into each intermediary, as for example suppliers of a low type know they have low probability to pass the test of an intermediary of a high type. This explains how intermediaries of trust will compete based on the perception of the quality of the sites they certify.

Open questions This article does not deal with the analysis of the incentive for suppliers to produce goods of a high quality when the intermediary confiscates some of their surplus. Albano and Lizzeri (2001) show that while the intermediary improves the information that buyers have about the quality of the supplier's good, quality is underprovided relative to full information.

The intermediary must limit its share of the surplus in order to provide an incentive for the supplier to produce goods of a high quality, which leads to a study of how the terms of trade are set between the supplier and the consumer after the intermediary put them in contact. There is indeed a problem of re-negotiation of the terms of trade between the buyer and the seller if those that were concluded at the intermediary cannot be monitored afterwards. Suppliers may use the intermediary to contact consumers, and then bypass it to conclude the transaction. There is indeed an information revelation problem as it may not be possible for the intermediary to prove that a trade took place and on what terms. This makes a commission-based contract difficult to implement.

This is why the intermediary will prefer getting the terms of trade determined at the same time as the two parties are put in contact; it will not leave that determination to negotiation between the two parties after matching. Alternatively, the intermediary can make sure all negotiations occur under its watch. The intermediary then determines the terms of trade through the choice of who is allowed to meet, whether they are allowed to break off negotiation, or by setting the level of compensation for the breakup of negotiations. E-Bay (Resnick and Zeckhauser 2002) is a case study of the variety of choice an intermediary can propose to a consumer; buyers and sellers choose what selling/buying mechanism they are going to use (auction, fixed price, with insurance, without insurance, ...) and then decide which buyer/seller to trade with, based at least in part on 
which mechanism was chosen. Nadel (2000) provides a discussion of how Internet intermediaries adopt different strategies that provide for different levels of objectivity in the advice provided to consumers.

Other interesting areas for research include the strategies of consumers, who may be able to take advice from several intermediaries (multi-homing) and gather multiple reports. They may also visit consumers' fora and compare their experience at various intermediaries. Consumers' fora can also be more credible than any intermediary, due to the number of reports gathered there and the lack of an incentive for any consumer to lie about its experience (Chen, Fay, and Wang 2003). What then motivates consumers to report their experience? Can any one supplier influence the tone of the reports about its product or the product of competitors by posing as consumers?

Models also generally assume that a false report by an intermediary necessarily means it was lying. However, suppliers may be able to prevent the intermediary from gaining perfect knowledge of their type and it is then difficult to attribute a mistake to the intermediary or to the seller.

Finally, government may adopt regulation and impose remedies to maintain and improve intermediation services. The government does play a role in the regulation of digital markets. It sets the allowed amount of advertising (anti-spam regulations), limits or encourages competition in markets for information, mandates the certification of products and ensures minimum levels of truthfulness in advertising. That role may also be partially left to private organizations that will set and monitor standards (see Lerner and Tirole (2004)). More broadly, Strömberg (2002) discusses the interplay between media and public policy.

\section{References}

Albano, G. L., And A. Lizzeri (2001): "Strategic Certification and Provision of Quality," International Economic Review, 42(1), 267-283. 
Armstrong, M. (2002): “Competition in Two-Sided Markets,” Oxford University.

BARON, D., AND D. BESANKo (1984): "Regulation, Asymmetric Information, and Auditing," Rand Journal of Economics, 15(4), 447-470.

BAYE, M., AND J. MORGAN (2001): "Information gatekeepers on the Internet and the competitiveness of homegeneous product markets," American Economic Review, 91(3), 454-474.

Caillaud, B., And B. Jullien (2001): “Competing Cybermediaries,” European Economic Review, 45, 797-808.

(2003): “Chicken and Egg: competition among intermediation service providers," Rand Journal of Economics, 34(2), 309-328.

Chen, Y., S. FAY, AND Q. WANG (2003): "Marketing implications of online consumer product reviews," University of Florida Working Paper.

Crawford, V., ANd J. Sobel (1982): “Strategic Information Transmission,” Econometrica, 50(6), 1431-1451.

GAUdEul, A. (2003): “Internet intermediaries' editorial content quality," University of Toulouse.

Grossman, G. (1981): “The informational role of warranties and private disclosure,” Journal of Law and Economics, 24, 461-483.

GuERRA, G. (2001): “Certification Disclosure and Informational Efficiency: A case for Ordered Ranking of Levels,” Discussion Paper Series, Number 64.

Henshaw, R. (2001): “What next for Internet Journals?," First Monday, 6(9).

HVIDE, H. (2002): “Segmentation and pricing behavior in a market for certification," Norwegian School of Economics and Business. 
Khalil, F., And J. Lawarree (1995): “Collusive Auditors,” The American Economic Review, $85(2), 442-446$.

LERnER, J., AND J. TiROLE (2004): "A model of forum shopping with special reference to standard setting organizations,” NBER Working Paper No. w10664.

LIZZERI, A. (1999): "Information revelation and certification intermediaries," Rand Journal of Economics, 30, 214-231.

Milgrom, P. (1981): "Good news and bad news: representation theorems and applications," The Bell Journal of Economics, 12(2), 380-391.

NAdEL, M. (2000): “The Consumer Product Selection Process in an Internet Age : Obstacles to Maximum Effectiveness and Policy Options," Harvard Journal of Law and Technology, 14(1), $185-264$.

Okuno-Fujiwara, M., A. Postlewaite, and K. Suzumura (1990): “Strategic Information Revelation," Review of Economic Studies, 57(1), 25-47.

PEYRACHE, E., AND L. QUESADA (2003): “Reputation of a potentially collusive auditor,” HEC Paris and University of Wisconsin-Madison.

— (2004): “Strategic certification," HEC Paris and University of Wisconsin-Madison.

Resnick, P., ANd R. ZECKhauser (2002): “Trust Among Strangers in Internet Transactions: Empirical Analysis of eBay's Reputation System," in The Economics of the Internet and ECommerce. Amsterdam, Elsevier Science.

Rochet, J.-C., And J. Tirole (2002): “Cooperation among Competitors: The Economics of Payment Card Associations," Rand Journal of Economics, 33(4), 1-22.

_ (2004): “Two-Sided Market: an Overview,” University of Toulouse (IDEI).

Strausz, R. (2003): "Honest Certification and the Threat of Capture," Free University of Berlin. 
StrömberG, D. (2002): "Mass Media Competition, Political Competition, and public policy," Review of Economic Studies, 71(1), 265-284.

The Economist (2000): "Survey on E-Commerce," The Economist, Feb 24th 2000, http://www.economist.com/surveys/showsurvey.cfm?issue=20000226.

WOLINSKY, A. (1993): “Competition in a market for informed experts' services,” Rand Journal of Economics, 24(3), 380-398.

\section{A Outline of Lizzeri's proof}

If

$$
E(t / t \geq x)-E(t) \geq E(t / t \leq x), \forall x \in[0,1]
$$

then the intermediary can use a certification method that ensure favorable beliefs by the consumer: it will certify the highest type 1 as type 1 with probability $p$ close to 1 , while certifying all other suppliers of type $t<1$ as $t$ with probability $q$ close to 0 . In that case, the type 1 supplier goes to the intermediary. It will not be alone to do so because if it was, then going to the intermediary would be a sure signal you are of type 1, and other suppliers would be motivated to go to the intermediary (indeed, $q$ is low enough that their true type is not revealed often, while $p<1$ makes it credible that a supplier who is not certified may still be of type 1). There is therefore a cutoff point $x$ such that suppliers with $t>x$ go to $I$. The condition on $F$ ensures they make higher profits by getting certified and paying $E(t)$ than by not going to the intermediary. By progressive unraveling of suppliers behaviors (any supplier of type $t=x-\varepsilon, \varepsilon$ small, will want to get confused with suppliers of type $t \geq x$ and make higher profits), $x=0$. Therefore, suppliers find themselves forced into a behavior that benefits the intermediary, and consumers cannot thus entertain alternative, less favorable, beliefs about the behavior of supplier. 